Gut, 1972, 13, 289-292

\title{
Partial nodular transformation of the liver presenting with ascites
}

\author{
A. P. DICK AND G. A. GRESHAM \\ From Addenbrooke's Hospital, Cambridge
}

SUMMARY Partial nodular transformation of the liver is a rare condition. Only six cases have been reported previously, all of which presented with bleeding from oesophageal varices. A further example of the disorder is recorded differing in the mode of onset with ascites. The total duration of the illness was eight weeks. Necropsy showed widespread evidence of liver cell damage with nodule formation around the hilum. These nodules had caused portal venous obstruction and ascites.

In 1966 Sherlock, Feldman, Moran, and Scheuer described four cases of a liver disorder characterized by multiple nodules in the perihilum which caused symptoms by interference with the hepatic circulation. All four cases presented with bleeding from oesophageal varices, as did two further cases since described (Maillard, Potet, and Benhamon, 1967; Classen, Elster, Pesch, and Demling, 1970).

The following case is reported in view of the rarity of the condition and the different mode of presentation with ascites. This was due to portal vein compression, which had also caused thrombosis of branches of the splenic vein and splenic infarction.

\section{Case Report}

G.S., the patient, a 45-year-old housewife, was admitted on 9 September 1970 to Addenbrooke's Hospital with a history of the sudden onset of abdominal swelling accompanied by nausea three weeks before. The swelling had increased and one week before admission she developed dull, aching central abdominal pain and diarrhoea with about six loose stools of normal colour daily. There had been slight weight loss. Menses had ceased 18 months previously. She had no past history of note apart from an appendectomy. She had never been on a contraceptive pill. She had three children now aged 20 to 23.

Examination showed a thin, but not unwelllooking woman with a protuberant abdomen. There were signs of ascites. No oedema and no other abnormality was found. Urine contained no albumin. Investigations on admission: haemoglobin $11.8 \mathrm{~g} \%$, ESR (Westergren) $32 \mathrm{~mm} /$ one hour, white cell count

Received for publication 12 January 1972.
$6,400(94 \%$ neutrophils, $1 \%$ eosinophils, $3 \%$ lymphocytes, $2 \%$ monocytes). Blood urea $21 \mathrm{mg} \%$, electrolytes normal. Bilirubin was less than $0.5 \mathrm{mg} \%$, alkaline phosphatase $11 \mathrm{KA}$ units, SGPT 38 units, plasma proteins $6.8 \%$, normal electrophoretic pattern. A chest radiograph showed that both domes of the diaphragm were raised. On 10 September a barium enema was normal.

By two days after admission the ascites had increased substantially and paracentesis was performed, 6 litres of clear straw-coloured fluid being withdrawn. Lymphocytes and red cells, but no malignant cells, were seen on microscopy. Fluid was sterile on culture and no tubercle bacilli were grown: protein content $1 \cdot 1 \mathrm{~g} \%$.

No abnormality was found on gynaecological examination but laparoscopy showed that the omentum appeared to be covering a large epigastric mass. A barium meal on 16 September showed no intrinsic abnormality in the stomach or duodenum. A liver scan with technetium 99 colloid on 18 September showed a rather poor count rate, the liver displaced medially by ascites and some areas of reduced emission. An Se 75 selenomethionine scan at the same time showed no definite pancreatic uptake.

After the first few days in hospital the patient's general condition deteriorated. She was drowsy and lethargic and at times semi-comatose but had no features suggestive of a local neurological lesion. She subsequently improved slightly and an exploratory laparotomy was performed on 2 October. Extensive thickening of the retroperitoneal tissues was found together with ascites and infarction of the spleen. No other local lesion was found. Biopsy of paracaecal fat showed oedematous fibro-fatty tissue. After the 
operation she became markedly hyponatraemic. The electrolytes were restored but her general condition slowly deteriorated with increasing mental confusion and drowsiness. She died on 13 October.

\section{Necropsy Findings (P70/660)}

The body was that of a well nourished, middle-aged woman showing slight pitting oedema of the lower legs. The peritoneal cavity contained half a litre of cloudy, pale yellow fluid and a few fibrinous adhesions between coils of small gut. Both small and large intestines were oedematous. The portal vein was thickened and dilated ( $2 \mathrm{~cm}$ diameter); the splenic vein was dilated $(0.8 \mathrm{~cm}$ diameter $)$ forming an aneurysmal sac at the splenic hilum (Fig. 1). Recent thrombus blocked branches of the splenic vein at the hilum and there was extensive recent infarction of the spleen. There were raised linear varices at the lower end of the oesophagus. The main portal vein was compressed by nodules of liver tissue, the largest $4 \times 5 \mathrm{~cm}$ (Fig. 2). The liver weighed $1280 \mathrm{~g}$ and the entire cut surface was faintly nodular and yellowbrown. A tortuous dilated splenic artery $(0.4 \mathrm{~cm}$ diameter) contained a thin-walled aneurysm $(2 \mathrm{~cm}$ diameter) near the splenic hilum. The biliary system was normal.

The heart $(200 \mathrm{~g})$ was normal. Both pleural sacs contained yellow-pink fluid $(250 \mathrm{ml}$ in the left; 100 $\mathrm{ml}$ in the right); oedematous lungs. The urogenital,

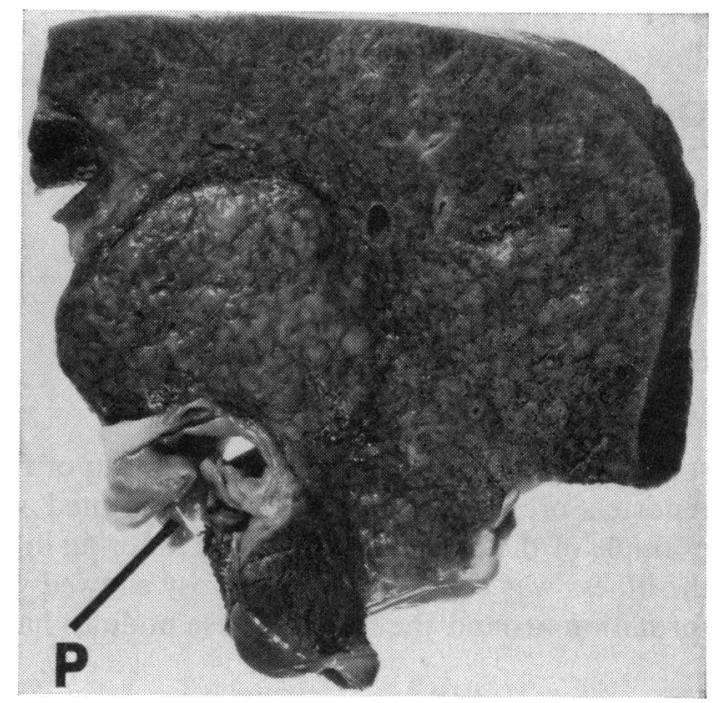

Fig. 2 Nodule in the porta hepatis adjacent to the portal vein $(\mathrm{P})$.

endocrine, lymphoreticular, skeletal, and central nervous systems were not remarkable.

\section{Histopathology}

There was a moderate degree of fatty change

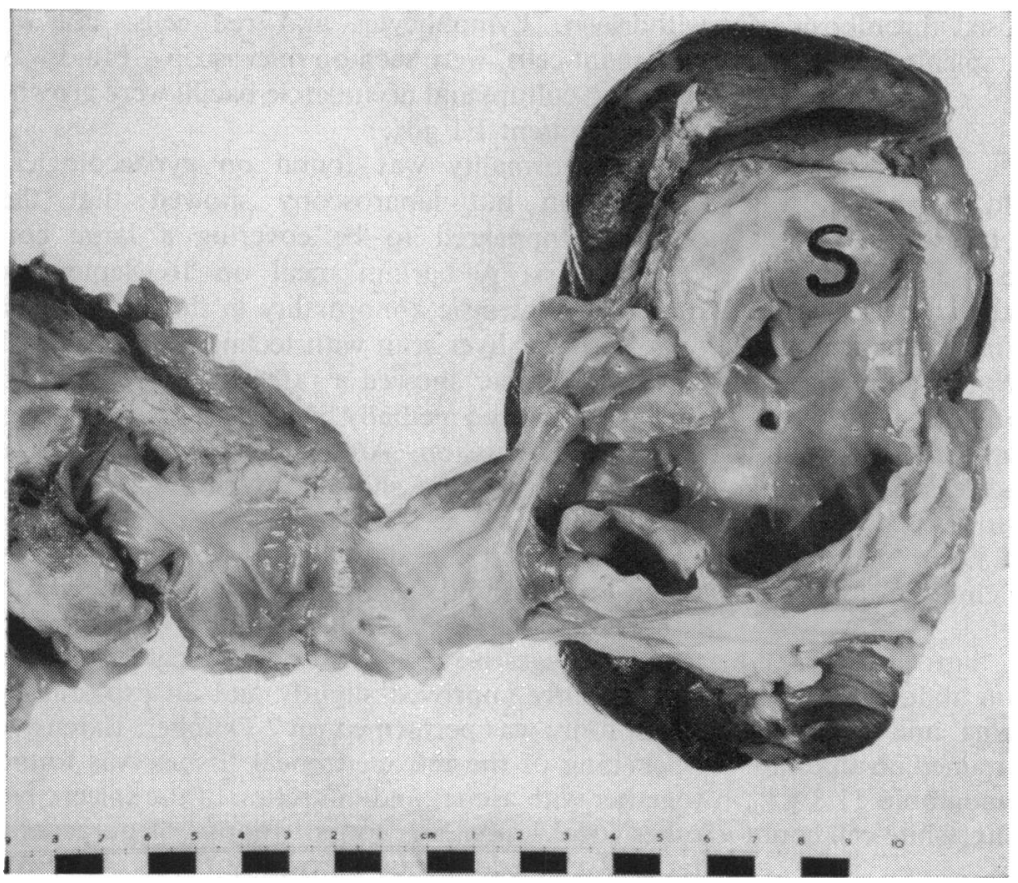

Fig. 1 Great dilatation of the splenic vein (S) at the hilum of the spleen. 


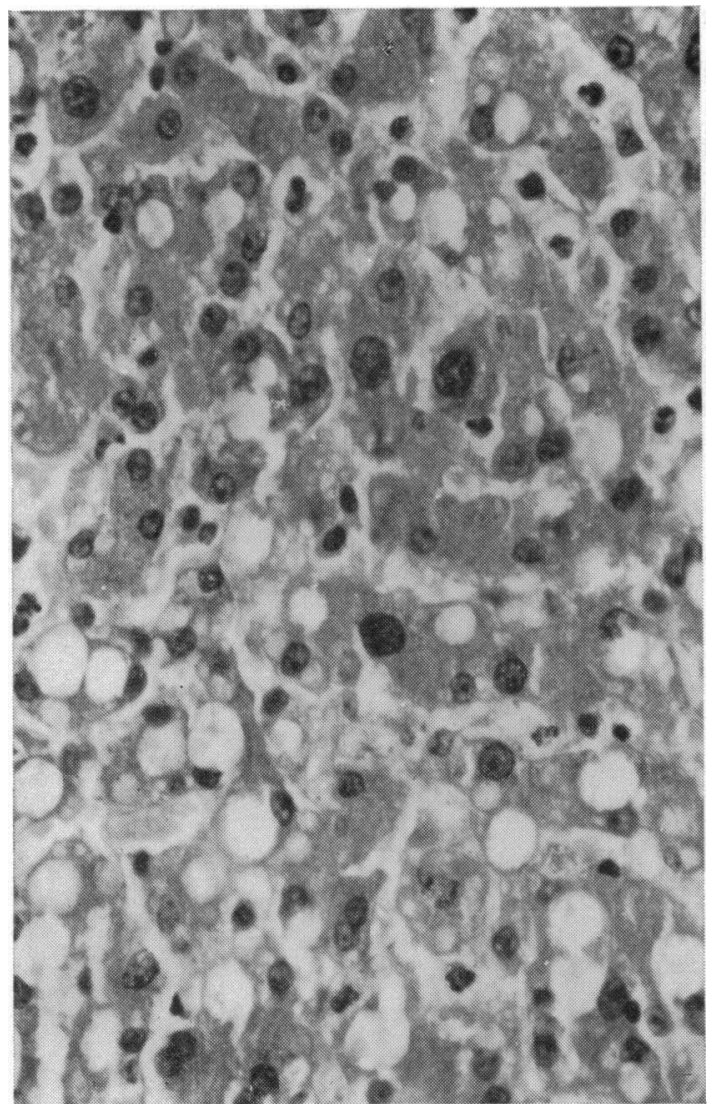

Fig. 3

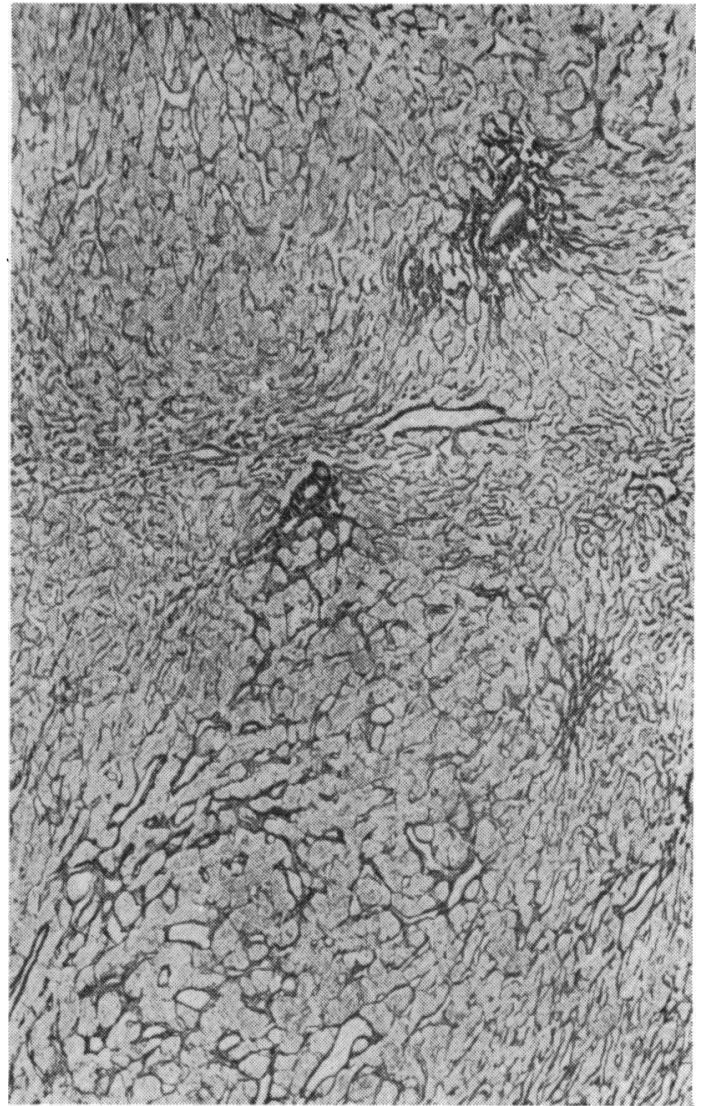

Fig. 4

Fig. 3 Fatty change and pleomorphic nuclei in liver (haematoxylin and eosin $\times 200$ ).

Fig. 4 Irregular arrangement of portal tracts and reticulin framework in a portal nodule (Gordon and Sweets reticulin method $\times 100$ ).

throughout the liver and sections from all parts showed groups of pleomorphic regenerating liver cells with hyperchromatic nuclei (Fig. 3). Section of the portal nodules showed similar appearances but here the portal tracts were irregularly arranged and some were sclerotic (Fig. 4). Another feature of this area was conspicuous intimal fibro-elastic thickening of portal veins, including the main vein. These changes, like the splenic artery aneurysm, were probably secondary to pressure upon vessels in the porta hepatis.

Sections of spleen showed recent infarction and the lungs revealed early bronchopneumonia, recent thrombi in small vessels, and abundant megakaryocytes in capillaries. There were many dilated veins in the sections of the lower oesophagus. Other organs were examined but did not show any significant histological abnormalities.

\section{Discussion}

The outstanding clinical feature of this case was the development of ascites in a hitherto healthy woman leading to a suspected diagnosis of intraabdominal neoplasia. In this respect, our case differs from others in which bleeding from oesophageal varices has been the initial symptom.

At necropsy it was only in the region of the porta hepatis that definite nodules were seen. Microscopically they contained portal tracts and hepatic veins though the arrangement was haphazard suggesting either a hamartomatous malformation or that irregular foci of regeneration had developed. In and near the nodules portal vessels showed intimal thickening which was not found elsewhere in the liver. This supports the view that the nodules had caused local pressure upon veins. 
Liver cell damage was widespread in our case but only in one part had an exuberant, nodular, regenerative process appeared and caused portal venous obstruction. Partial nodular transformation is an entirely appropriate description for this process but the aetiology remains obscure.
References

Classen, M., Elster, K., Pesch, H. J., and Demling, L. (1970). Portal hypertension caused by partial nodular transformation of the liver. Gut, 11, 245-249.

Maillard, J. N., Potet, F., and Benhamon, J. P. (1967). Transformation nodulaire partielle du foie avec hypertension portale. Presse méd., 75, 2799-2802.

Sherlock, S., Feldman, C. A., Moran, B., and Scheuer, P. J. (1966). Partial nodular transformation of the liver with portal hypertension. Amer. J. med., 40, 195-203. 